\title{
STRATEGI PEMASARAN PADA PT. INDOMARCO ADI PRIMA STOCK POINT GADING CEMPAKA NON PASAR (SP. GCNP) BENGKULU
}

\author{
Freddy Firmansyah Marpaung \\ Sulisti Afriani \\ Program Studi Manajemen \\ Fakultas Ekonomi Universitas Dehasen Bengkulu
}

\begin{abstract}
ABSTRAK
Freddy Firmansyah Marpaung, Sulisti Afriani; Analisis SWOT untuk diterapkan pada strategi pemasaran di PT. Indomarco Adi Prima Stock Point Gading Cempaka Non Pasar (SP. GCNP) Bengkulu. Metode pengumpulan data yang digunakan yaitu metode kuesioner dengan menyebarkan daftar pertanyaan kepada responden. Metode analisis yang digunakan adalah analisis SWOT untuk mengetahui faktor-faktor internal (kekuatan dan kelemahan) dan faktorfaktor eksternal (peluang dan ancaman), yang kemudian akan dimasukkan ke dalam matriks SWOT. Dari hasil penelitian maka diperoleh nilai 9.7 untuk kekuatan dan 6.51 untuk peluang yang menunjukkan posisi kuadaran PT. Indomarco Adi Prima Stock Point Gading Cempaka Non Pasar (SP. GCNP) Bengkulu berada pada kuadran 1 atau kuadran yang memakai strategi turn agresif yaitu situasi yang sangat menguntungkan buat PT. Indomarco Adi Prima SP. GCNP karena memiliki kekuatan yang besar sehingga dapat memanfaatkan peluang yang ada.
\end{abstract}

\begin{abstract}
Freddy Firmansyah Marpaung, Sulisti Afriani; Method of data collection used method of questionnaire to distribute a list of questions to the respondent. Method of analysis used is SWOT that aims to identify factors internal factors (strengths and weaknesses) and external factors (opportunities and threats) are then inserted into the SWOT matrix. From the results it obtained a score of 9.7 for strength and 6.51 for the opportunities that indicate the quadrant position PT. Indomarco Adi Prima Stock Point Gading Cempaka Non Pasar (SP. GCNP) Bengkulu is in quadrant 1 or quadrant taking a turn aggressive strategy that is very favorable situation for PT. Indomarco Adi Prima Stock Point Gading Cempaka Non Pasar (SP. GCNP) Bengkulu because it has enormous power that can take advantage of existing opportunities.
\end{abstract}

\section{Key Words: Marketing Strategy, SWOT}

\section{PENDAHULUAN}

Setiap perusahaan harus mengetahui perubahan lingkungan yang terjadi karena hal tersebut sangat penting untuk menentukan strategi yang akan diterapkan dalam mencapai tujuan yaitu memperoleh keuntungan. Untuk itu diperlukan perencanaan yang matang dalam mencapai tujuan tersebut. Semakin mudah suatu lingkungan berubah, maka dampak terhadap perubahan strategi semakin besar. Tingkat persaingan yang terjadi antar perusahaan tak lepas dari strategi pemasaran yang diterapkan, baik dalam usaha pengenalan produknya maupun usaha merebut pasar (konsumen).

Pemasaran adalah keseluruhan intern yang berhubungan dengan kegiatan-kegiatan usaha yang bertujuan untuk merencanakan, menentukan harga, mempromosikan dan mendistribusikan barang dan jasa yang akan memuaskan kebutuhan pembeli, baik pembeli yang ada maupun pembeli yang potensial (Stanton, 2013:83). Pemasaran adalah kegiatan manusia yang diarahkan pada usaha untuk memuaskan keinginan dan kebutuhan melalui proses pertukaran.

Strategi pemasaran pada dasarnya adalah rencana menyeluruh, terpadu dan menyatu di bidang pemasaran yang memberikan panduan tentang kegiatan yang akan dijalankan untuk 
dapat tercapainya tujuan pemasaran suatu perusahaan. Dengan kata lain strategi pemasaran adalah serangkaian tujuan dan sasaran kebijaksanaan serta aturan yang memberi arah kepada usaha pemasaran dalam menghadapi lingkungan dan keadaan persaingan yang selalu berubahubah.

PT. Indomarco Adi Prima merupakan salah satu unit bisnis dari PT. Indofood Sukses Makmur Tbk yang bergerak di bidang distribusi consumer product. PT. Indomarco Adi Prima mendistribusikan mayoritas dari produk Indofood, dan juga mendistribusikan consumer product lainnya non Indofood ke beberapa area di Indonesia, ke pasar modern, ke pasar tradisional, daerah pinggir jalan, sampai daerah pelosok. PT.Indomarco Adi Prima mendistribusikan barang food dan nonfood seperti Mie instan, Susu Kental Manis, Baby food, Cooking oil, Deterjen, Margarine, bumbu instan dan lain sebagainya. PT. Indomarco Adi Prima melakukan pemasaran produk-produk melalui sistem yang terarah dan terpadu. PT. Indomarco Adi Prima melakukan pemasaran ke toko-toko yang telah menjadi langganan.

Di Bengkulu kota PT. Indomarco Adi Prima memiliki 6 stock point dan 1 kantor cabang. Salah satu stock point yang akan di teliti oleh penulis adalah stock point Gading Cempaka Non Pasar (SP. GCNP) yang berada di jalan Kebun Veteran, yang memiliki jumlah toko 150 aktif, yang dikunjungi setiap semingu sekali dan ada yang dua minggu sekali. Ruang lingkup daerah pemasaran stock point Gading Cempaka Non Pasar (SP. GCNP) meliputi Kebun Veteran, Simpang Skip, Sawah Lebar, Kebun Tebeng, jalan Merapi, Tanah patah, Lempuing, Padang Harapan dan Lingkar Barat. Dan tenaga pemasar barang (salesman) memiliki target penjualan yang diberikan perusahaan setiap bulannya. Dan di stock point Gading Cempaka Non Pasar (SP. GCNP) memilki dua tenaga pemasar/salesman yang berbeda divisi produk yaitu salesman bagian divisi noodle dan salesman divisi non noodle, sehingga tenaga pemasar di PT. Indomarco memiliki fokus untuk melakukan penjualan dan pendistribusian produk-produk.

Berdasarkan uraian di atas maka judul yang akan di angkat dalam penelitian ini adalah "Strategi Pemasaran Pada PT. Indomarco Adi Prima Stock Point Gading Cempaka Non Pasar (GCNP) Bengkulu.

\section{TINJAUAN LITERATUR}

\section{Strategi Pemasaran}

Menurut Assauri (2010:168), strategi pemasaran pada dasarnya adalah rencana yang menyeluruh, terpadu dan menyatu di bidang pemasaran, yang memberikan panduan tentang kegiatan yang akan dijalankan untuk dapat tercapainya tujuan pemasaran suatu perusahaan. Menurut Prawirosentono (2009:26), strategi pemasaran adalah serangkaian kebijakan pemasaran yang terpadu dan terarah yang jadi pedoman kegiatan berbagai jenjang unit pemasaran untuk mencapai target penjualan dalam wilayah pemasaran tertentu, sesuai dengan perubahan kondisi dan lingkungan usaha bisnis bersangkutan. Strategi pemasaran adalah pendekatan pokok yang akan digunakan oleh unit bisnis dalam mencapai sasaran yang telah ditetapkan lebih dahulu, di dalamnya tercantum keputusan-keputusan pokok mengenai target pasar, penempatan produk di pasar, bauran pemasaran dan tingkat biaya pemasaran yang dilakukan (Daryanto,2013:157). Dalam strategi pemasaran ada tiga faktor yang menyebabkan terjadinya perubahan dalam strategi pemasaran yaitu :

1. Daur hidup produk, Setiap perusahaan harus melakukan strategi agar produk yang dimiliki tidak membuat konsumen jenuh. Sehingga perusahaan akan selalu berpikir untuk menciptakan produk lain yang sama fungsinya.

2. Posisi persaingan antar perusahaan di pasar.Setiap perusahaan harus memperhatikan posisi perusahaan dalam persaingan apakah memimpin, menantang, mengikuti atau hanya mengambil sebagian kecil dalam persaingan di pasar.

3. Situasi ekonomi. Perusahaan yang baik adalah perusahaan yang selalu memperhatikan situasi ekonomi dalam pasar serta cara pandang ke masa depan, apakah perekonomian negara berada dalam kondisi makmur atau inflasi yang tinggi. 


\section{Jenis-jenis Strategi Pemasaran}

Menurut Assauri (2010:179), dalam hubungan strategi pemasaran secara umum, dapat dibedakan tiga jenis strategi pemasaran yang dapat ditempuh perusahaan, yaitu :

a. Strategi pemasaran yang tidak membeda-bedakan pasar

Dengan strategi ini, perusahaan menganggap pasar sebagai suatu keseluruhan, sehingga perusahaan hanya memperhatikan kebutuhan konsumen secara umum. Oleh karena itu, perusahaan hanya menghasilkan dan memasarkan satu macam produk saja dan berusaha menarik semua pembeli dan calon pembeli dengan rencana pemasaran saja. Strategi ini bertujuan untuk melakukan penjualan secara massal sehinga menurunkan biaya operasional.

b. Strategi pemasaran yang membeda-bedakan pasar (Differentiated Marketing).

Dengan Strategi ini, perusahaan hanya melayani kebutuhan beberapa kelompok konsumen tertentu dengan jenis produk tertentu pula. Perusahaan atau produsen menghasilkan dan memasarkan produk yang berbeda-beda untuk tiap segmen pasar. Strategi ini bertujuan untuk mempertebal kepercayaan kelompok tertentu terhadap produk yang dihasilkan dan dipasarkan, sehingga pembeliannya akan dilakukan berulang kali.

c. Strategi pemasaran yang terkonsentrasi (Concentrated Marketing).

Strategi ini mengkhususkan pemasaran produknya dalam beberapa segmen pasar dengan pertimbangan keterbatasan sumber daya perusahaan. Keuntungan penggunaan strategi ini adalah perusahaan diharapkan akan memperoleh keuntungan karena spesialisasi dalam produksi, distribusi dan usaha promosi sehingga apabila segmen pasar dipilih secara tepat.

\section{Analisis SWOT (Stength, Weakness, Opportunity, Threats)}

Analisis SWOT merupakan suatu penyempurnaan pemikiran dari berbagai kerangka kerja dan rencana strategi (frame work and strategic planning) yang pernah diterapkan baik di medan pertempuran maupun bisnis. Menurut Rangkuti (2006:18) Analisis SWOT adalah identifikasi berbagai faktor secara sistematis untuk merumuskan strategi perusahaan. Analisis ini didasarkan pada logika yang dapat memaksimalkan kekuatan (Strength) dan peluang (Opportunity), namun secara bersamaan dapat meminimalkan kelemahan (Weakness) dan ancaman (Threats).

a. Strength adalah kekuatan internal yang dimiliki perusahaan, keterampilan relatif terhadap pesaing (Competitor) dan kebutuhan pasar yang dilayani perusahaan. Kekuatan dapat terkandung dalam : Kekuatan Finansial, Memiliki SDM yang baiK, Penerapan teknologi, Citra positif perusahaan, Kepemimpinan pasar dan Hubungan perusahaan dengan konsumen

b. Weakness adalah kelemahan, keterbatasan dan kekurangan internal perusahaaan dalam finansial, sumber daya manusia, penerapan teknologi sehingga menghambat kinerja perusahaan.

c. Opportunity adalah peluang atau situasi penting yang menguntungkan dari luar perusahaan. Sumber dari situasi penting dari luar perusahaan yaitu : Kebijakan pemerintah, Gaya hidup maupun budaya masyarakat, Bertambahnya jumlah penduduk dan Meningkatnya jumlah pendapatan masayarakat

d. Threats adalah ancaman atau situasi penting yang tidak menguntungkan dari luar perusahaan (External) yang menjadi hambatan perusahaan. Berbagai contoh ancaman yang dihadapi oleh perusahaan antara lain : Masuknya pesaing baru (New Competitor), Lambatnya pertumbuhan pasar, Perkembangan dan perubahan teknologi yang belum dikuasai dan Perubahan peraturan perundangan yang sifatnya restriktif.

Perencanaan disusunkan berdasarkan hasil analisis SWOT merupakan antisipasi yang tepat untuk menghadapi perubahan lingkungan usaha dan untuk mengatur strategi serta untuk mencari tukang pasar. Menurut Rangkuti (2006:22), sebelum membuat matrik ini terlebih dahulu harus mengetahui faktor strategi eksternal (EFAS) dengan langka-langka sebagai berikut:

a. Menyusun faktor peluang dan ancaman pada kolom 1.

b. Memberikan bobot pada masing-masing faktor pada kolom 2, mulai dari 1,0 (sangat penting) sampai dengan 0,10 (tidak penting). Bobot dari semua faktor strategis yang berupa peluang dan ancaman ini harus berjumlah 1. 
c. Menghitung rating dalam (kolom 3) untuk masing-masing faktor dengan memberi skala mulai dari 5 (sangat baik/outstanding) sampai dengan 1 (sangat tidak baik/ poor) berdasarkan pengaruh faktor tersebut pada kondisi organisasi. Pemberian nilai rating untuk peluang bersifat positif, artinya peluang yang semakin besar diberi rating +5 , tetapi jika peluangnya kecil diberi +1 . Sementara untuk rating ancaman bersifat sebaliknya, yaitu jika nilai ancaman besar, maka ratingnya -5 jika nilai ancamannya kecil, maka nilainnya -1 .

d. Mengalikan bobot faktor pada kolom 2 dengan rating pada kolom 3. Hasilnya adalah pembobotan untuk masing-masing faktor.

e. Menghitung jumlah skor pembobotan. Nilai ini adalah untuk memetakan posisi organisasi organisasi pada diagram analisis SWOT.

Menurut Rangkuti (2006:24), untuk merumuskan faktor-faktor strategis internal (IFAS)

tersebut dalam kerangka strength dan weakness perusahaan dengan tahapan sebagai berikut :

a. Tentukan faktor-faktor yang menjadi kekuatan serta kelemahan perusahaan pada kolom 1 .

b. Beri bobot masing-masing faktor tersebut dengan skala mulai dari 1,0 (paling penting) sampai 0,1 (tidak penting), berdasarkan pengaruh-pengaruh faktor-faktor tersebut jumlahnya tidak boleh melebihi skor total 1,00.

c. Hitung rating (dalam kolom 3) untuk masing-masing faktor dengan memberikan skala mulai dari 5 (outstanding) sampai dengan 1 (poor) berdasarkan pengaruh faktor tersebut terhadap kondisi perusahaan yang bersangkutan. Pemberian nilai rating untuk faktor kekuatan bersifat positif (kekuatan yang semakin besar diberi rating +5 , tetapi kekuatan yang kecil diberi rating +1). Begitu juga jika nilai kelemahan sangat besar, ratingnya adalah 5 dan jika nilai kelemahannya sedikit ratingnya 1.

d. Kalikan bobot pada kolom 2 dengan rating pada kolom 3, untuk memperoleh skor masingmasing faktor yang nilainya bervariasi mulai dari 5,0 (outstanding) sampai dengan 1,0 (poor). Menyusun dan menentukan faktor-faktor strategis ekternal dan internal suatu perusahaan. Untuk menghitung nilai bobot, rating dan skor untuk tabel faktor-faktor strategi internal dan faktor-faktor strategi eksternal, dengan teknik skala sebagai berikut:

1) Bobot

$$
\begin{aligned}
& 1,00=\text { sangat penting } \\
& 0,75=\text { penting } \\
& 0,50=\text { standar } \\
& 0,25=\text { tidak penting } \\
& 0,10=\text { sangat tidak penting }
\end{aligned}
$$

2) Rating

5 = sangat baik

$4=$ baik

$3=$ netral

2 = tidak baik

\begin{tabular}{|c|c|c|c|}
\hline Uraian & Bobot & Rating & Skor \\
\hline \multicolumn{4}{|l|}{ I. Strengths (Kekuatan) } \\
\hline \begin{tabular}{l|l} 
& 1. Item dari Strengths
\end{tabular} & & & \\
\hline 2. Item dari Strengths & & & \\
\hline \multicolumn{4}{|l|}{ II. Weaknessess (Kelemahan) } \\
\hline \begin{tabular}{l|l} 
& 1. Item dari Weaknesses \\
\end{tabular} & & & \\
\hline $\begin{array}{ll}\text { 2. Item dari Weaknesses } \\
\end{array}$ & & & \\
\hline \multicolumn{4}{|l|}{ III. Opportunities (Peluang) } \\
\hline \begin{tabular}{|l|l|} 
& 1. Item dari Opportunities \\
\end{tabular} & & & \\
\hline 2. Item dari Opportunities & & & \\
\hline \multicolumn{4}{|l|}{ IV. Threats (Ancaman) } \\
\hline \begin{tabular}{l|l} 
& 1. Item dari Threats \\
\end{tabular} & & & \\
\hline 2. Item dari Threats & & & \\
\hline
\end{tabular}

1 = sangat tidak baik

3) Untuk menghitung nilai skor menggunakan formulasi sebagai berikut:

Skor = Bobot $\mathrm{x}$ Rating

Tabel 4. Format Analisis SWOT Untuk Faktor Internal dan Eksternal

Sumber : Fahmi (2011:223) 
Dalam menyusun strategi pemasaran perusahaan harus menggunakan alat tertentu. Menurut Rangkuti (2006:31), matriks SWOT adalah alat yang dipakai untuk menyusun faktorfaktor strategis perusahaan. Matriks SWOT menggambarkan bagaimana manajemen dapat mencocokkan peluang-peluang dan ancaman-ancaman eksternal yang dihadapi suatu perusahaan tertentu dengan kekuatan dan kelemahan internalnya untuk menghasilkan 4 rangkaian alternatif strategis. Matriks ini dapat menghasilkan 4 set kemungkinan alternatif strategis, dapat di lihat pada tabel berikut ini :

Tabel 2. Matriks SWOT

\begin{tabular}{|c|c|c|}
\hline EFAS & $\begin{array}{l}\text { Kekuatan } \\
\text { Strengths (S) } \\
\text { Menentukan } \\
\text { kekuatan internal }\end{array}$ & $\begin{array}{l}\text { Kelemahan } \\
\text { Weaknesses }(\mathbf{W}) \\
\text { Menentukan } \\
\text { kelemahan internal }\end{array}$ \\
\hline $\begin{array}{l}\text { Peluang } \\
\text { Oppourtunity (0) } \\
\text { Menentukan faktor-faktor } \\
\text { peluang eksternal }\end{array}$ & $\begin{array}{llr}\text { Strategi SO } & & \\
\text { Ciptakan } & \text { strategi } & \text { yang } \\
\text { menggunakan } & \text { kekuatan } & \text { untuk } \\
\text { memanfaatkan } & \text { peluang } & \text { sebaik- } \\
\text { baiknya. } & & \\
\end{array}$ & $\begin{array}{l}\text { Strategi Wo } \\
\text { Menciptakan strategi yang } \\
\text { meminimalisirkan kelemahan } \\
\text { dengan memanfaatkan peluang } \\
\text { yang ada. }\end{array}$ \\
\hline $\begin{array}{l}\text { Ancaman Threats (T) } \\
\text { Menentukan faktor-faktor } \\
\text { ancaman eksternal }\end{array}$ & $\begin{array}{ll}\text { Strategi ST } & \\
\text { Menciptakan strategi } & \text { yang } \\
\text { menggunakan kekuatan } & \text { untuk } \\
\text { mengatasi ancaman. } & \\
\end{array}$ & $\begin{array}{l}\text { Strategi WT } \\
\text { Menciptakan strategi yang } \\
\text { meminimalkan kelemahan untuk } \\
\text { menghindari kelemahan. }\end{array}$ \\
\hline
\end{tabular}

Sumber : Rangkuti (2006:31)

Keterangan :

1. Strategi SO

Strategi ini dibuat berdasarkan jalan pikiran perusahaan yaitu dengan memanfaatkan seluruh kekuatan yang dimiliki perusahaan untuk merebut dan memanfaatkan peluang sebesar-besarnya.

2. Strategi ST

Strategi ini adalah strategi dalam menggunakan kekuatan yang dimiliki perusahaan untuk mengatasi ancaman yang ada di luar dari perusahaan.

3. Strategi WO

Strategi ini diterapkan berdasarkan pemanfaatan peluang yang ada dengan cara meminimalkan kelemahan yang ada di dalam perusahaan.

4. Strategi WT

Strategi ini didasarkan pada kegiatan yang bersifat defensif dan berusaha meminimalkan kelemahan yang ada serta menghindari ancaman.

\section{Kerangka Analisis}

\begin{tabular}{|l|l|}
\hline \multicolumn{1}{|c|}{ Analisis SWOT } \\
Faktor Internal : \\
Strength/Kekuatan \\
Weakness/Kelemahan \\
Faktor Eksternal \\
Opportunity/Peluang \\
Threats/Ancaman
\end{tabular}

\section{HASIL PENELITIAN DAN PEMBAHASAN}

\section{Analisis SWOT}

\section{Faktor Internal}

Dalam memasarkan produk-produk PT. Indomarco Adi Prima kepada konsumen maka sangat perlu menentukan strategi yaitu membuat analisa yang meliputi kekuatan 
(strengths), kelemahan (weaknesses) yang dimiliki oleh PT. Indomarco Adi Prima stock point Gading Cempaka Non Pasar (SP. GCNP) Bengkulu. Analisa kekuatan dan kelemahan yang terdapat di PT. Indomarco Adi Prima Bengkulu adalah sebagai berikut:

1. Kekuatan (Strengths)

a) Tenaga kerja yang terampil dan berpengalaman dalam pemasaran.

Tenaga kerja pemasar (salesman) yang dimiliki oleh PT. Indomarco Adi Prima memiliki keterampilan dalam melakukan transaksi penjualan dan berpengalaman serta telah dilatih dalam konsolidasi.

b) Memiliki produk-produk yang beraneka jenis.

Produk-produk yang dijual oleh PT. Indomarco Adi Prima sangat banyak jenisnya, sehingga toko selalu memesan barang yang diperlukan setiap minggunya.

c) Memiliki jaringan distribusi yang luas.

Jaringan distribusi PT. Indomarco Adi Prima sangat luas, sampai ke pelosok di daerah Bengkulu. Karena PT. Indomarco Adi Prima memakai sistem stock point yang berada di tiap titik kecamatan atau kabupaten.

d) Memiliki sarana transportasi dalam jumlah yang memadai.

Sarana transportasi yang dimiliki oleh PT. Indomarco Adi Prima sudah memadai, yang bertujuan untuk pengantaran barang ke toko sampai dengan tepat waktu dan tidak melewati 1 minggu.

e) Adanya divisi khusus penjualan produk noodle dan divisi non noodle.

Di setiap stock point PT. Indomarco Adi Prima memiliki 2 salesman yang berbeda divisi yaitu divisi noodle dan divisi non noodle, tujuannya adalah agar salesman memiliki fokus terhadap produk yang di jualnya.

2. Kelemahan (Weaknesses)

a) Adanya karyawan yang bekerja kurang produktif dari segi antaran barang ke outlet. Kelemahan dari segi pengantaran barang ke outlet bukan karena alat transportasi yang kurang memadai, tetapi adanya karyawan yang mengalami kejenuhan dalam pekerjaannya sebagai delivery, hal ini yang harus di benahi oleh perusahaan.

b) Insentif yang tidak begitu besar untuk karyawan, sehingga tidak ada motivasi dalam bekerja. Adanya insentif yang tidak begitu besar membuat karyawan tidak memiliki semangat untuk mengejar target yang diberikan oleh perusahaan.

c) Bentuk bangunan kantor dan gudang yang sangat sederhana. PT. Indomarco Adi Prima selalu memilih kantor dan gudang yang dekat dengan daerah pasar atau toko-toko dengan biaya yang murah walaupun seperti kurang layak bagi distributor yang sekelas nasional.

d) Adanya hama tikus di dalam gudang yang dapat merusak produk. Kurangnya antisipasi dari karyawan gudang mengenai hama tikus, sering membuat barang yang ada di gudang mengalamai keadaan barang yang tidak layak.

e) Kurangnya perhatian ke toko langganan dalam bentuk memberi bonus Tunjangan Hari Raya. PT. Indomarco Adi Prima memberikan tunjangan hari raya hanya kepda toko yang memberikan sumbangsi penjualan yang besar, sehingga toko yang berbelanja kecil tidak diberikan tunjangan hari raya.

\section{Faktor Eksternal}

Dalam memasarkan produk indofood dan non indofood kepada konsumen sangat dibutuhkan strategi, maka harus menganalisis peluang (Opportunity) dan ancaman (Threats) yang akan dihadapi oleh PT. Indomarco Adi Prima Stock Point Gading Cempaka Non Pasar (SP. GCNP) Bengkulu. Analisa ini disebut SWOT analisa yaitu sebagai berikut:

1) Peluang (Opportunity)

a) Merek produk-produk yang di jual oleh PT. Indomarco Adi Prima sudah dikenal oleh masyarakat. Produk-produk yang dijual oleh PT. Indomarco Adi Prima sudah dikenal oleh masyarakat dan tidak susah untuk memasarkan produk-produk tersebut.

b) Bertambahnya jumlah toko di daerah pinggiran.Bertambahnya jumlah toko di daerah pinggiran menjadi peluang bagi PT. Indomarco Adi Prima untuk menyebarluaskan distribusi barang. 
c) Tingginya minat masyarakat terhadap produk-produk yang dijual oleh PT. Indomarco Adi Prima SP. GCNP Bengkulu.Minat masyarakat yang tinggi untuk membeli produk-produk PT. Indomarco membuat perusahaan menjadi lebih percaya diri dalam memasarkan produk-produk tersebut.

d) Perusahaan distributor mendapat izin resmi dari pemerintah.

PT. Indomarco Adi Prima memiliki izin resmi dari pemerintah untuk melakukan transaksi jual beli kepada toko tanpa adanya larangan.

e) Bertambahnya jumlah penduduk di daerah pinggiran kota Bengkulu. Bertambahnya jumlah penduduk di daerah pinggiran membuat PT. Indomarco Adi Prima lebih fokus untuk mengusai pangsa pasar di daerah pinggiran kota bengkulu

2) Ancaman (Threats)

a) Adanya distributor yang menjadi pesaing PT. Indomarco Adi Prima. Selain dari PT. Indomarco Adi Prima yang menjadi distributor kebutuhan rumah tangga, ada juga distributor yang menjadi pesaing yang dapat menghambat pendistribusian produkproduk PT. Indomarco Adi Prima.

b) Keadaan ekonomi masyarakat yang tidak stabil. Keadaan ekonomi masyarakat Bengkulu yang tidak stabil, membuat perusahaan mencari strategi agar tidak terkena imbas dari musim sepi/paceklik.

c) Kemajuan sistem pemasaran dari distributor lain seperti door prize. Sistem pemasaran yang dilakukan oleh perusahaan distributor lain dengan memberikan door prize, sangat mengganggu penjualan PT. Indomarco Adi Prima Bengkulu.

d) Banyaknya produk-produk yang menjadi barang substitusi. Selain produk-produk yang dijual PT. Indomarco Adi Prima, perusahaan pesaing juga menciptakan produk yang serupa yang dapat menjadi barang pengganti.

e) Adanya harga produk kompetitor yang lebih murah.

Selain menjadi barang pengganti, perusahaan pesaing juga memberikan harga yang lebih murah dari harga produk yang dijual oleh PT. Indomarco Adi Prima. Sehingga dapat membuat pertumbuhan penjualan produk-produk yang dijual oleh PT. Indomarco Adi Prima terhambat.

\section{Perhitungan IFAS}

Dari uraian diatas, maka dapat dikelompokkan dan dicari nilai dari interval faktor analysis strategy (IFAS) pada PT. Indomarco Adi Prima Stock Point Gading Cempaka Non Pasar (SP.GCNP) Bengkulu, yaitu baik untuk bobot maupun rating berdasarkan alternatif jawaban responden antara lain:

\section{Tabel 6. Alternatif Jawaban Responden Terhadap IFAS}

\begin{tabular}{|l|l|c|c|}
\hline No & \multicolumn{1}{|c|}{ Alternatif Jawaban } & Bobot & Rating \\
\hline 1. & STS (Sangat Tidak Setuju) & 0,10 & 1 \\
\hline 2. & TS (Tidak Setuju) & 0,25 & 2 \\
\hline 3. & N (Netral) & 0,50 & 3 \\
\hline 4. & S(Setuju) & 0,75 & 4 \\
\hline 5. & SS(Sangat Setuju) & 1,00 & 5 \\
\hline
\end{tabular}

Sumber: Fahmi (2011:223)

Untuk memperoleh bobot pada faktor internal kekuatan dan kelemahan maka hasil jawaban responden internal 5 orang dikalkulasikan dengan mengalihkan jawaban atas setiap pertanyaan dengan skala yang telah ditentukan yaitu 1,00 sangat penting sampai dengan 0,10 sangat tidak penting kemudian dibagi dengan jumlah responden 5 orang. Begitu juga untuk mencari rating tetapi yang berbeda adalah jawaban atas setiap pertanyaan diberi skala mulai dari 5 sangat baik sampai dengan 1 sangat tidak baik, lalu dibagi jumlah responden 5 orang. Lalu untuk menghitung skor dengan cara mengalihkan bobot dengan rating. Dapat dilihat pada tabel di bawah ini : 
1) Kekuatan(Strengths)

Tabel 7. Kekuatan (Strengths)

\begin{tabular}{|l|c|c|c|l|}
\hline \multicolumn{1}{|c|}{ Uraian } & Bobot & Rating & Skor & Komentar \\
\hline Kekuatan (Strengths) & 0.95 & 4.8 & 4.56 & Kekuatan \\
\hline $\begin{array}{l}\text { 1. Tenaga kerja yang terampil dan } \\
\text { berpengalaman dalam pemasaran. }\end{array}$ & 1.00 & 5 & 5.00 & Kekuatan \\
\hline 2. Memiliki produk-produk yang beraneka jenis. & 1.00 & 5 & 5.00 & Kekuatan \\
\hline 3. Memiliki jaringan distribusi yang luas. & 0.90 & 4.6 & 4.14 & Kekuatan \\
\hline $\begin{array}{l}\text { 4. Memiliki sarana transportasi dalam jumlah } \\
\text { yang memadai. }\end{array}$ & 0.95 & 4.8 & 4.56 & Kekuatan \\
\hline $\begin{array}{l}\text { 5. Adanya divisi khusus penjualan produk noodle } \\
\text { dan divisi non noodle. }\end{array}$ & $\mathbf{4 . 8}$ & $\mathbf{2 4 . 2}$ & $\mathbf{2 3 . 2 6}$ & \\
\hline \multicolumn{2}{|l|}{ Jumlah } & & & \\
\hline
\end{tabular}

Sumber: hasil penelitian dan diolah, 2015

2) Kelemahan (Weaknesses)

\section{Tabel 8. Kelemahan (Weaknesses)}

\begin{tabular}{|l|c|c|c|c|}
\hline \multicolumn{1}{|c|}{ Uraian } & Bobot & Rating & Skor & Komentar \\
\cline { 1 - 3 } Kelemahan (Weaknesses) & & & & \\
\cline { 1 - 3 } $\begin{array}{l}\text { 1. Adanya karyawan yang bekerja kurang } \\
\text { produktif dari segi antaran barang ke toko. }\end{array}$ & 0.60 & 3.4 & 2.04 & Bukan Kelemahan \\
\hline $\begin{array}{l}\text { 2. Insentif yang tidak begitu besar untuk } \\
\text { karyawan, sehingga tidak ada motivasi } \\
\text { dalam bekerja. }\end{array}$ & 0.85 & 4.4 & 3.74 & Kelemahan \\
\hline $\begin{array}{l}\text { 3. Bentuk bangunan kantor dan gudang yang } \\
\text { sangat sederhana. }\end{array}$ & 0.80 & 4.2 & 3.36 & Kelemahan \\
\hline $\begin{array}{l}\text { 4. Adanya hama tikus di dalam gudang yang } \\
\text { dapat merusak produk. }\end{array}$ & 0.70 & 3.8 & 2.66 & Kelemahan \\
\hline $\begin{array}{l}\text { 5. Kurangnya perhatian ke toko langganan } \\
\text { dalam bentuk memberi bonus Tunjangan } \\
\text { Hari Raya. }\end{array}$ & 0.55 & 3.2 & 1.76 & Bukan Kelemahan \\
\hline
\end{tabular}

Sumber: hasil penelitian dan diolah, 2015

\section{Perhitungan EFAS}

Dan untuk mencari nilai dari perhitungan External Factor Analysis Strategy (EFAS), berikut ini adalah tabel strategi pemasaran untuk faktor eksternal yang terdiri atas Peluang (Opportunities) dan Ancaman (Threats) yang terjadi pada PT. Indomarco Adi Prima Stock Point Gading Cempaka Non Pasar (SP. GCNP) Bengkulu.

Untuk memperoleh bobot pada faktor eksternal peluang dan ancaman maka hasil jawaban responden eksternal 30 orang dikalkulasikan dengan mengalihkan setiap jawaban dengan skala yang telah ditentukan yaitu mulai 1,00 sangat setuju, 0.75 setuju, 0.5 netral, 0.25 tidak setuju sampai dengan 0,10 sangat tidak setuju kemudian dibagi dengan jumlah responden yang terdiri atas 30 orang.

Dan untuk mencari rating yaitu hasil jawaban responden 30 orang dari setiap pertanyaan dijumlahkan dengan mengalihkan jawaban dari setiap pertanyaan dengan skala yang telah ditentukan mulai dari 5 sangat setuju sampai dengan 1 sangat tidak setuju, kemudian dibagi jumlah responden 30 orang. Setelah memperoleh bobot dan rating maka dapat memperoleh skor dengan cara mengalihkan bobot dengan rating. Dapat dilihat pada tabel dibawah ini: 
1) Peluang (Opportunities)

Tabel 9. Peluang (Opportunities)

\begin{tabular}{|l|c|c|c|c|}
\hline \multicolumn{1}{|c|}{ Uraian } & Bobot & Rating & Skor & Komentar \\
\hline Peluang (Opportunities) & 0.86 & 4.46 & 3.84 & Peluang \\
\hline $\begin{array}{l}\text { 1. Merek produk-produk yang di jual oleh } \\
\text { PT. Indomarco Adi Prima sudah dikenal } \\
\text { oleh masyarakat. }\end{array}$ & 0.69 & 3.76 & 2.59 & Peluang \\
\hline $\begin{array}{l}\text { 2. Bertambahnya jumlah toko di daerah } \\
\text { pinggiran. }\end{array}$ & 0.76 & 4.06 & 3.08 & Peluang \\
\hline $\begin{array}{l}\text { 3ingginya minat masyarakat terhadap } \\
\text { produk-produk yang dijual oleh PT. } \\
\text { Indomarco Adi Prima SP. GCNP } \\
\text { Bengkulu. }\end{array}$ & 0.78 & 4.13 & 3.22 & Peluang \\
\hline $\begin{array}{l}\text { 4. Perusahaan distributor mendapat izin } \\
\text { resmi dari pemerintah. }\end{array}$ & 0.73 & 3.9 & 2.85 & Peluang \\
\hline $\begin{array}{l}\text { 5. Bertambahnya jumlah penduduk di } \\
\text { daerah pinggiran kota Bengkulu. }\end{array}$ & 3.82 & $\mathbf{2 0 . 3 1}$ & $\mathbf{1 5 . 5 8}$ & \\
\hline
\end{tabular}

Sumber: hasil penelitian dan diolah, 2015

2) Ancaman (Threats)

Tabel 10. Ancaman (Threats)

\begin{tabular}{|l|c|c|c|c|}
\hline \multicolumn{1}{|c|}{ Uraian } & Bobot & Rating & Skor & Komentar \\
\hline Ancaman (Threats) & 0.71 & 3.83 & 2.72 & Ancaman \\
$\begin{array}{l}\text { 1. Adanya distributor yang menjadi } \\
\text { pesaing PT. Indomarco Adi Prima. }\end{array}$ & 0.64 & 3.56 & 2.28 & $\begin{array}{c}\text { Bukan } \\
\text { Ancaman }\end{array}$ \\
\hline $\begin{array}{l}\text { 2. Keadaan ekonomi masyarakat yang } \\
\text { tidak stabil. }\end{array}$ & 0.47 & 2.86 & 1.34 & $\begin{array}{c}\text { Bukan } \\
\text { Ancaman }\end{array}$ \\
\hline $\begin{array}{l}\text { 3. Kemajuan sistem pemasaran dari } \\
\text { distributor lain seperti door prize. }\end{array}$ & 0.46 & 2.86 & 1.32 & $\begin{array}{c}\text { Bukan } \\
\text { Ancaman }\end{array}$ \\
\hline $\begin{array}{l}\text { 4. Banyaknya produk-produk yang } \\
\text { menjadi barang substitusi. }\end{array}$ & 0.48 & 2.93 & 1.41 & $\begin{array}{c}\text { Bukan } \\
\text { Ancaman }\end{array}$ \\
\hline $\begin{array}{l}\text { 5. Adanya harga produk kompetitor yang } \\
\text { lebih murah. Jumlah }\end{array}$ & $\mathbf{2 . 7 6}$ & $\mathbf{1 6 . 0 4}$ & $\mathbf{9 . 0 7}$ & \\
\hline
\end{tabular}

Sumber: hasil penelitian dan diolah, 2015

\section{Matriks SWOT (Strength, Weakness, Opportunity, Threats)}

Dari hasil analisis SWOT, maka dapat disusun tabel matrik SWOT yang terdiri dari empat strategi usaha yaitu SO,WO, ST dan WT, masing-masing strategi memiliki karakteristik tersendiri dan hendaknya dalam implementasi strategi dilakukan secara bersama-sama dan saling mendukung satu sama lain.

Matriks SWOT dilakukan dengan memasukkan seluruh poin strengths, weaknesses, opportunities dan threats ke dalam matriks lalu membaginya ke dalam empat usaha dengan mengalokasikan hasil dari perkalian bobot dan rating ke dalam strategi SO, WO, ST dan WT yang merupakan kombinasi dari semua kekuatan, kelemahan, peluang dan ancaman yang dihadapi oleh PT. Indomarco Adi Prima Stock Point Gading Cempaka Non Pasar (Sp. GCNP) Bengkulu. 
Tabel 11. Strategi Pemasaran dalam Faktor Internal dan Eksternal

\begin{tabular}{|c|c|c|}
\hline EFAS & $\begin{array}{l}\text { Kekuatan (Strengths/S) } \\
\text { 1. Tenaga kerja yang terampil } \\
\text { dalam pemasaran. } \\
\text { 2. Memiliki produk-produk yang } \\
\text { beraneka jenis. } \\
\text { 3. Memiliki jaringan distribusi } \\
\text { yang luas. } \\
\text { 4. Memiliki sarana transportasi } \\
\text { dalam jumlah yang memadai. } \\
\text { 5. Adanya divisi khusus } \\
\text { penjualan }\end{array}$ & $\begin{array}{l}\text { Kelemahan (Weaknesses/W) } \\
\text { 1. Insentif yang tidak begitu } \\
\text { besar untuk karyawan, } \\
\text { sehingga tidak ada motivasi } \\
\text { dalam bekerja. } \\
\text { 2. Bentuk bangunan kantor dan } \\
\text { gudang yang sangat } \\
\text { sederhana. } \\
\text { 3. Adanya hama tikus di dalam } \\
\text { gudang yang dapat merusak } \\
\text { produk. }\end{array}$ \\
\hline $\begin{array}{l}\text { Peluang (Opportunities/0) } \\
\text { 1. Merek produk-produk yang di jual } \\
\text { sudah dikenal. } \\
\text { 2. Bertambahnya jumlah toko. } \\
\text { 3. Tingginya minat masyarakat } \\
\text { terhadap produk yang di jual. } \\
\text { 4. Perusahaan distributor mendapat } \\
\text { izin resmi dari pemerintah. } \\
\text { 5. Bertambahnya jumlah penduduk di } \\
\text { Bengkulu. }\end{array}$ & $\begin{array}{l}\text { Strategi SO } \\
\text { Yaitu perusahaan harus melatih } \\
\text { tenaga kerja agar terampil, } \\
\text { mengembangkan } \\
\text { produk, distribusi } \\
\text { mempertahankan produk-produk } \\
\text { yang telah dikuasai. } \\
\text { Agar permintaan pasar terpenuhi } \\
\text { dan menguasai pangsa pasar. }\end{array}$ & $\begin{array}{l}\text { Strategi WO } \\
\text { Yaitu perusahaan harus } \\
\text { memberikan insentif yang layak } \\
\text { dan memberikan tempat kantor } \\
\text { dan gudang yang layak supaya } \\
\text { karyawan memiliki semangat } \\
\text { dalam bekerja sehingga peluang } \\
\text { yang ada dapat tercapai dengan } \\
\text { mudah. }\end{array}$ \\
\hline $\begin{array}{l}\text { Ancaman (Threats/T) } \\
\text { 1. Adanya distributor yang menjadi } \\
\text { pesaing PT. Indomarco Adi Prima. }\end{array}$ & $\begin{array}{l}\text { Strategi ST } \\
\text { Selalu menjaga kualitas produk } \\
\text { dan menjalin hubungan yang baik } \\
\text { kepada konsumen, agar dapat } \\
\text { menguasai pangsa pasar, dan } \\
\text { menghambat jalur distribusi } \\
\text { pesaing. }\end{array}$ & $\begin{array}{l}\text { Strategi WT } \\
\text { Perusahaan harus memberikan } \\
\text { motivasi dan promosi kepada } \\
\text { karyawan agar karyawan tidak } \\
\text { menjadi lesu dalam bekerja. }\end{array}$ \\
\hline
\end{tabular}

Sumber: hasil penelitian dan diolah, 2015

\section{Diagram Analisis SWOT (Strength, Weakness, Opportunity, Threats)}

Dari analisis SWOT diatas maka dapat dibuat suatu ringkasan dari perhitungan untuk melihat seberapa besar kekuatan, kelemahan, peluang dan ancaman yang terjadi pada PT. Indomarco Adi Prima Stock Point Gading Cempaka Non Pasar (SP. GCNP) Bengkulu.

Tabel 12. Rekapitulasi IFAS dan EFAS

\begin{tabular}{|l|l|l|l|l|}
\hline \multirow{2}{*}{ Keterangan } & \multicolumn{2}{|c|}{ IFAS } & \multicolumn{2}{c|}{ EFAS } \\
\cline { 2 - 5 } & Strengths & Weaknesses & Opportunities & Threats \\
\hline $\begin{array}{l}\text { Strategi } \\
\text { pemasaran }\end{array}$ & 23.26 & 13.56 & 15.58 & 9.07 \\
\hline Kuadran & \multicolumn{2}{|c|}{$23.26-13.56=9.7$} & \multicolumn{2}{c|}{$15.58-9.07=6.51$} \\
\hline
\end{tabular}

Sumber: hasil penelitian dan diolah, 2015

Keterangan dari tabel diatas menjelaskan strategi pada PT. Indomarco Adi Prima Stock Point Gading Cempaka Non Pasar (SP. GCNP) Bengkulu. Hasil dari penjumlahan, maka kekuatan (Strengths) yang dimiliki PT. Indomarco Adi Prima Stock Point Gading Cempaka Non Pasar (SP. GCNP) Bengkulu adalah 23.26 sedangkan kelemahan (Weaknesses) adalah 13.56, jadi kuadran internal faktor analysis strategy (IFAS) yaitu 23.26 - $13.56=9.7$. Peluang (Opportunities) yang dimiliki dari strategi tersebut sebesar 15.58, untuk ancaman (Threats) sebanyak 9.07, jadi kuadran external factor analysis strategy (EFAS) yaitu $15.58-9.07=6.51$ sehingga posisi perusahaan berada pada kuadran 1 dalam diagram analisis SWOT.

Dengan posisi tersebut, meskipun menghadapi berbagai macam ancaman PT. Indomarco Adi Prima Stock Point Gading Cempaka Non Pasar (SP. GCNP) Bengkulu tetap berada pada kuadran Internal dengan menerapkan strategi yaitu menggunakan kekuatan untuk memanfaatkan peluang jangka panjang dengan cara strategi agresif (growth oriented strategy). Diagram SWOT akan menunjukkan pada posisi manakah strategi pemasaran pada PT. Indomarco Adi Prima Stock Point Gading Cempaka Non Pasar Bengkulu saat ini. Posisi strategi 
inilah yang akan menentukan letak kuadran strategi pemasaran PT. Indomarco Adi Prima Stock Point Gading Cempaka Non Pasar (SP. GCNP) Bengkulu. Letak kuadran tersebut akan dijadikan fundamental analisis strategi ke depan, kuadran-kuadran dapat diamati secara jelas melalui diagram analisis SWOT berikut ini:

\section{Gambar 10. Diagram hasil analisis SWOT}

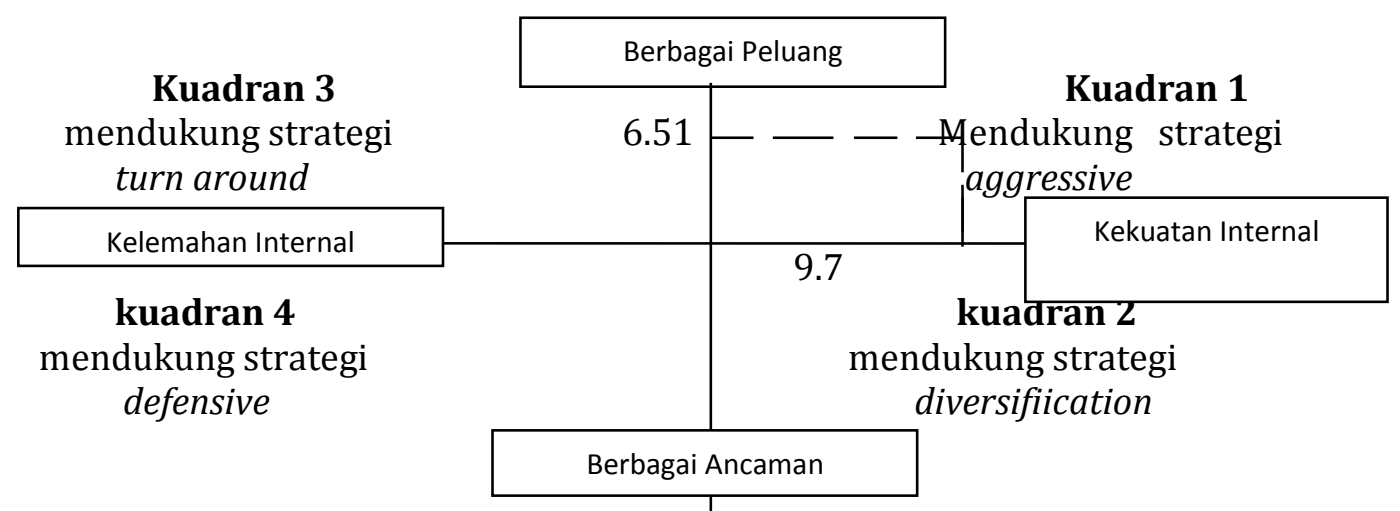

Sumber : hasil penelitian dan diolah, 2015

Berdasarkan diagram diatas maka titik berada pada kuadran 1, yaitu PT. Indomarco Adi Prima Stock Point Gading Cempaka Non Pasar (SP. GCNP) Bengkulu memiliki peluang dan kekuatan yang besar sehingga dapat memanfaatkan peluang yang ada dengan memanfaatkan keuatan yang ada. Strategi yang diterapkan dalam kondisi ini adalah mendukung kebijaksanaan yang agresif (growth oriented strategy) yaitu dengan cara:

1. Mendorong karyawan untuk terus bekerja lebih giat lagi dan memberikan insentif yang besar sebagai motivasi dalam bekerja buat karyawan.

2. Perusahaan dapat memanfaatkan kekuatan internal yang ada di dalam perusahaan yaitu produk-produk yang beraneka jenis, alat transportasi yang memadai dan tenaga kerja yang terampil dalam memasarkan barang.

3. Perusahaan tetap menjaga hubungan yang baik dengan konsumen (faktor eksternal) yaitu dengan memberikan pelayanan berupa produk yang masih tersegel, pengantaran barang yang selalu tepat waktu, komunikasi yang terjalin baik, dapat mereturn barang yang sudah ekspired/kondisi yang sudah tidak layak lagi, memajang/display produk yang ada di toko sehingga peluang yang di miliki perusahaan distributor lain semakin kecil.

\section{Kesimpulan}

Berdasarkan hasil penelitian yang telah dilakukan pada PT. Indomarco Adi Prima Stock Point Gading Cempaka Non Pasar (SP. GCNP) Bengkulu, maka dapat disimpulkan strategi yang sesuai yaitu: Strategi agresif atau strategi SO karena PT. Indomarco Adi Prima Stock Point Gading Cempaka Non Pasar (SP. GCNP) Bengkulu saat ini memiliki kekuatan dan peluang yang besar, maka strategi inilah yang dapat digunakan untuk kemajuan PT. Indomarco Adi Prima Stock Point Gading Cempaka Non Pasar (SP. GCNP) Bengkulu, meliputi:

1. Menambah jumlah toko yang berada di dalam daerah pemasaran PT. Indomarco Adi Prima Stock Point Gading Cempaka Non Pasar (SP. GCNP) dan mengganti toko yang tidak produktif lagi dari segi penjualan serta dari segi pembayaran tagihan supaya jaringan distribusi menjadi luas.

2. Menjaga kualitas produk dan selalu menjaga agar stok produk tetap tersedia di gudang PT. Indomarco Adi Prima Stock Point Gading Cempaka Non Pasar (SP. GCNP).

3. Memberikan pelatihan dan bimbingan tenaga kerja bagian pemasaran dan office baik yang baru masuk maupun yang sudah lama bekerja.

4. Memberikan pelayanan kepada toko dari segi pengantaran barang yang tepat waktu dan memberikan pelayanan dari segi pereturan barang dan dari segi pemajangan barang, serta menjalin komunikasi yang baik. 


\section{Saran}

Untuk pengembangan PT. Indomarco Adi Prima Stock Point Gading Cempaka Non Pasar (SP. GCNP) Bengkulu, maka ada beberapa hal yang disarankan sebagai berikut:

1. Menaikkan insentif karyawan yang selama ini dirasa kurang mencukupi, supaya kinerja dan kesejahteraan karyawan meningkat.

2. Meningkatkan kualitas pelayanan kepada toko agar konsumen tidak pindah ke produk pesaing.

3. Menjaga stock barang yang ada di gudang selalu dalam keadaan baik dan stocknya selalu tersedia.

\section{DAFTAR PUSTAKA}

Akbar, Lian. 2013. Strategi Pemasaran Dalam Meningkatkan Laba Pada Usaha Toko Bangunan Alih Jaya Kepahiang. Tesis Tidak Diterbitkan. Bengkulu Fakultas Ekonomi Universitas Dehasen Bengkulu.

Assauri, Sofjan. 2010. Manajemen Pemasaran. Edisi Sepuluh. Jakarta. Rajagrafindo Persada.

Daryanto. 2011. Sari Kuliah Manajemen Pemasaran. PT. Sarana Tutorial Nurani Sejahtera. Bandung.

Daryanto. 2013. Manajemen Pemasaran. Bandung. Sarana Tutorial Nurani Sejahtera. Bandung.

Fahmi, Irham. 2011. Manajemen Risiko. Bandung. Alfabeta

Fahmi, Irham. 2011. Manajemen Pengambilan Keputusan. Alfabeta. Bandung

Litalia, Lovi. 2013. Strategi Pemasaran Dalam Meningkatkan Jumlah Penjualan Pupuk Organik Pada PT. Sehasen Di Kecamatan Bermani Ilir Kabupaten Kepahiang. Tesis Tidak Diterbitkan. Bengkulu Program Studi Manajemen Unived Bengkulu.

Lestari, Rizka. 2014. Analisis Strategi Pemasaran Untuk Meningkatkan Penjualan Pada Depot Air Minum Asshidiq RO Kota Bengkulu. Skripsi tidak diterbitkan. Bengkulu Fakultas Ekonomi Universitas Dehasen.

Mursid, M. 2008. Manajemen Pemasaran. Jakarta. Bumi Aksara.

Prawirosentono, Suyadi. 2009. Manajemen Operasi, Analisis dan Studi Kasus. Edisi Keempat. Jakarta. Bumi Aksara.

Rangkuti, Freddy. 2006. Analisis SWOT Teknik Membedah Kasus Bisnis. Cetakan Kedua Belas. Jakarta. Gramedia Pustaka Utama.

Stanton, William J. 2013. Manajemen Pemasaran. Bandung. Sarana Tutorial $\quad$ Nurani Sejahtera. Sugiyono. 2007. Metodelogi Penelitian Bisnis. Jakarta. Alfabeta. 